\title{
SOME STUDIES ON TRYPANOSOMIASIS IN IMPORTED CAMELS
}

\author{
AHMED M.A. ZAITOUN ${ }^{1}$; SAFAA S. MALEK ${ }^{1}$; KHALED A.S. EL-KHABAZ ${ }^{1}$ and \\ SALHEEN G. ABD-EL-HAMEED ${ }^{2}$ \\ ${ }^{1}$ Infectious Diseases, Department of Animal Medicine, Faculty of Veterinary Medicine, Assiut University \\ ${ }^{2}$ Field Practitioner
}

Received: 15 November 2016; $\quad$ Accepted: 20 December 2016

\begin{abstract}
The present study was carried out to evaluate the percent of Trypanosoma evansi infection among imported camels from Sudan to Egypt during the period of investigation (13 months) in the quarantine period in Abu-Simbel Veterinary Quarantine at the South border of Egypt. A total number of 396 imported camels were inspected from September, 2014 till September, 2015, clinically examined and sampled for epidemiological studies using thin blood film and PCR techniques for diagnosis of Trypanosoma evansi. The clinical signs of the examined camels infected by Trypanosoma evansi were in acute form showing poor body condition, rising of body temperature up to $\left(38.81 \pm 0.05^{\circ} \mathrm{C}\right)$, Hyper-lacrimation with congestion of ocular membranes and edematous swelling in the lower parts of legs were the most prominent clinical findings. Signs of chronic form of Trypanosoma evansi were general debility and severe emaciation (disappearance of the hump, projections of ribs and atrophy of the muscles particularly thigh muscles), pale mucous membrane of conjunctivae with lacrimation, the camel was yawning, enlargement of lymph nodes particularly superficial cervical lymph nodes, edematous swelling in scrotal sacs with enlargement of testicles and edema in the base of neck and edematous and enlarged prolapsed penis and signs of balanoposthitis. Numerous ticks were parasitized camels infected with Trypanosoma evansi. The prevalence of Trypanosoma evansi infection using blood film technique was $12.17 \%$ among the clinically suspected cases and $0 \%$ among apparently healthy camels (overall prevalence 5.81\%). Whereas, the prevalence of Trypanosoma evansi infection using TBR $1 / 2$ primer-based PCR was reached $48 \%$ among clinically suspected camels and 20\% among apparently healthy camels (Total prevalence $43.3 \%$ ).
\end{abstract}

Key words: Camel, Trypanosma evansi, Prevalence, Egypt.

\section{INTRODUCTION}

Trypanosomiasis caused by Trypanosoma evansi is the most important single cause of morbidity and mortality in camels. The disease transmitted noncyclically by haematophagus flies (eg. Tabanus), and is endemic in Africa, Asia, central and SouthAmerica. Because of the wide spread of the disease, its control has attracted international attention, with focus on formulating and implementing effective strategies aimed at increasing productivity and achieving decrease in morbidity and mortality Obihiro, (1998). Trypanosomiasis is an acute/chronic disease of camel results progressive anaemia, anoxic condition and immunosuppression which later develops and predisposes the animal to other infections and death if untreated. It causes economic losses as a result of reduced productivity,

Corresponding author: Dr. SAFAA S. MALEK

E-mail address: safaamalek80@yahoo.com

Present address: Infectious Diseases, Department of Animal

Medicine, Faculty of Veterinary Medicine, Assiut University. abortion in all age groups of pregnancy period, and drop in milk and meat yield morbidity up to $30 \%$ and mortality of a round 3\%. In Egypt, the instability of local enzootic situation may be come into view through the massive inflow of imported Sudanese camels that may act as a continuous source of exotic Trypanosoma evansi infection El-Said et al. (1998). The accurate identification of camels infected by Trypanosoma evansi is a key factor in the success of any epidemiological surveillance or control program for Trypanosoma evansi infection among camels. The diagnosis of Trypanosoma evansi infection in camels follows the classical diagnostic methods for trypanosomoses involving clinical diagnosis, parasitological, serological as well as molecular techniques Tizard et al. (1979). The specific clinical diagnosis of trypanosomosis is difficult due to nonspecific clinical signs coupled with intermittent fever and low parasitaemias FAO, (2000). Diagnosis using PCR could offer a very precise method for detecting infection and discriminating between infected and non-infected animals. The aim of this study to 
determine the prevalence of Trypanosoma evansi infection among imported camels by using conventional thin blood film and evaluate Polymerase Chain Reaction.

\section{MATERIALS AND METHODS}

\section{AREA OF STUDY AND ANIMALS:}

Abu-Simbel Veterinary quarantine in Abu-Simbel city at southern of Aswan Governorate which representing the South border of Egypt and considered the major point of entry of the imported camel (Camelusdromedarius) particularly from Sudan and Ethiopia into Egypt. A total number of 396 imported camels (Camillus dromedarius) were studied at the period from September, 2014 till September, 2015. All imported Camels were male in relation to sex. All of camels were subjected to clinical examination according to Kohler- Rollesfon et al. (2001). They classified to clinically suspected cases that show abnormal clinical signs (Emaciation, Diarrhea, High body temperature, Mucous Membrane Paleness, Dullness, Edema and Rough coat), and clinically healthy, As shown in (Table 1).

\section{Thin blood smear:}

Ten $\mathrm{ml}$ of blood was collected from each animal into a tube with the anticoagulant (EDTA) by jugular venipuncture. Thin blood smears were prepared from each sample soon after collection, fixed with methanol, stained with Giemsa, and microscopically examined at 100x under oil following the procedures described by Sengupta et al. (2010).

\section{DNA EXTRACTION FROM BLOOD SAMPLES AND PCR AMPLIFICATION:}

DNA was extracted from whole blood samples according to Mahony et al. (2000). The PCR mixture $(25 \mu 1)$ contained $12.5 \mu 1$ GoTaq ${ }^{\circledR}$ Green Master Mix (Lot No: 0000062929, Promega, USA). $1.0 \mu 1$ Upstream Primer TBR-1, $1.0 \mu$ l Downstream Primer TBR-2, 5.0 $\mu$ l DNA templates and $5.5 \mu 1$ of nuclease free water. PCR was carried out foramplification of 164 bpbyusingahighly repeated sequenceofminichromosomesatel-lite DNATBR1/2(TBR1:5 GAATATTAAACAATGCGCAG-3 and TBR2:5 CCATTTATTAGCTTTGTTGC-3) (Masiga et al., 1992; Muieed et al., 2010 and Pruvot et al., 2010). The primer set (TBR1 \& TBR2) was specific for Trypanosomabrucei, but it would be useful especially outside the tsetse belt in which the kinetoplastic /or akinetoplastic Trypanosoma evansi were widely prevalent but not for Trypanosomabrucei as reported by Inoue et al. (1998). TBR1 \& TBR2 found in nucleus not in kinetoplast making results independent of the parasite kinetoplastic state and avoid the problem of failure targeting kDNA (Ventura et al., 2000 and Gonzales et al., 2003). The PCR amplification was performed as follows: initialcycle at $94 \circ \mathrm{C}$ for $1 \mathrm{~min}$ and then 30 cycles of denaturation at $94{ }^{\circ} \mathrm{C}$ for $30 \mathrm{~s}$, annealing at $60^{\circ} \mathrm{C}$ for $1 \mathrm{~min}$ and extension at $72{ }^{\circ} \mathrm{C}$ for $30 \mathrm{~s}$, and finallyonecycle at $72{ }^{\circ} \mathrm{C}$ for $2 \mathrm{~min}$. Desquesnes et al. (2001). The PCR products were analyzed by electrophoresis Through $1.5 \%$ agarose gel containing ethidium bromide $(0.5$ $\mathrm{g} / \mathrm{ml}$ ) and the image of the amplified DNA was captured using a gel documentation system (Biospectrum UVP, UK).

\section{RESULTS}

During the period of investigation from September, 2014 till September, 2015, Total number of 396 imported camels (Camillus dromedarius) were inspected and clinically examined during the quarantine measurements at Abu-Simbel Veterinary Quarantine Station. These imported camels were male in sex.

Out of 396 examined camels, 189 (47.73\%) cases showed clinical abnormalities and the remained cases $\mathbf{( 5 2 . 2 7 \% )}$ appeared to be clinically healthy. Blood samples of all camels with clinical abnormalities were microscopically examined for detection of Trypanosoma evansi infection and found that $\mathbf{2 3}(\mathbf{1 2 . 1 7 \%})$ cases were harbored infectionas shown in photo no. (10). The remained cases $(\mathbf{n}=\mathbf{1 6 6}, \mathbf{8 7 . 8 3 \%})$ were trypanosoma free by using blood film proceduresas showed in table (2). Approximately, $\mathbf{7 5 . 3 0 \%} \quad(\mathbf{n}=\mathbf{1 2 5})$ of the clinically suspected cases with negative results of blood film examination were subjected to molecular detection of Trypanosoma evansi infection using PCR based TBR $1 / 2$ primer. It was found that $60(48 \%)$ were positive and 65 $\mathbf{5 2 \% )}$ were negative to Trypanosoma evansi infection. On the other hand, all clinically healthy cases $(\mathbf{n}=\mathbf{2 0 7})$ of the examined camels $(\mathbf{n}=396)$ were subjected to blood film technique and they were trypanosoma free. Twenty five cases of the clinically healthy were randomly selected and subjected to PCR procedure. It was found that $5(\mathbf{2 0 \%})$ cases were positive and 20 $\mathbf{( 8 0 \% )}$ cases were negative to Trypanosomaevansi infection as showed in table (3).

The clinical signs of Trypanosoma evansi infection noticed were in acute form which representing $\mathbf{2 1 . 7 4 \%} \quad(5 / 23 \quad$ microscopically positive and clinically suspected). The chronic form was representing $\mathbf{7 8 . 2 6 \%} \quad(18 / 23$ microscopically positive and clinically suspected) indicating that the chronic form is more common than the acute form of the disease.

Signs of acute form of Trypanosoma evansi infection were: 
Poor body condition with muscular fatigue that interference standing-up and inability to walk to long distance with frequent recumbency. Regarding to the morning at 6.00 O'clock. Rectal temperature of the infected camels, there were rising of body temperature up to $\mathbf{( 3 8 . 8 1} \pm$ $\mathbf{0 . 0 5} \mathbf{C}$ ), it was higher than that recorded for the healthy camels $(\mathbf{3 6 . 7 1} \pm \mathbf{0 . 0 5} \mathbf{C})$. Hyperlacrimation with congestion of ocular mucous membranes during feverous condition in $\mathbf{8 . 6 8} \%$ (2/23) cases, highly characteristic. Edematous swelling in the lower parts of legs was $\mathbf{4 . 3 \%}$ $\mathbf{( 1 / 2 3 )}$ cases as shown in photo no. (1).

\section{Signs of chronic form of Trypanosoma evansi} infection were:

General debility and severe emaciation (disappearance of the hump and the hump appeared as a case filled with extra-soft gelatinous material. Remarkable appearance of the ribs (the ribs were well demarcated from the intercostal spaces), Atrophy of the thigh muscles) as shown in photo no. (2a\&b). The hump was bent to one side as shown in photo no. (3). Pale mucous membrane of conjunctivae. Lacrimation and there were gap between the eye ball and bone when press the tears down in $\mathbf{2 6 . 0 9 \%}(\mathbf{6} / 23)$ cases. Faeces were normal, or were sometime coated with mucus; and generally tapered faeces were noticed. The skin was remarkably dried, harsh and scurfy, as shown in photo no. (4). They were dullness, stretching of their neck and not response well to external stimulus. The camel was yawning and the tongue was pale or slightly bluish. Enlargement of lymph nodes particularly superficial cervical lymph nodes at the base of the neck in $\mathbf{2 1 . 7 4 \% ~} \mathbf{( 5 / 2 3 )}$ cases; sometimes surrounded with edematous area, as shownin photos no. (5a\&b). Edematous swelling was noticed in $\mathbf{3 0 . 4 3} \%(\mathbf{7 / 2 3})$ cases:

a- Edematous swelling at the base of neck in $\mathbf{1 3 . 0 4} \%(3 / 23)$ cases as shown in photo no. (6).

b- Edematous swelling in scrotal sacs with enlargement of testicles and the skin covering genital organs were rough (keratinized) and superficially fissured in $17.39 \%(\mathbf{4} / \mathbf{2 3})$ cases, as shown in photo no. (8a\&b). Edematous and Prolapsed Penis with disappearance of the characteristic hook shaped tip of the penis by closely examination and obvious signs of Balanoposthitis were observed in 13.04 \% (4/23) cases. The outer covering of the edematous penis were eroded and partially sloughed and there were grumbling with signs of pain during palpation, as shown in photo no. (7). Long hair of the humps was breaking-off or sloughed. $34.78 \%(8 / 23)$ of the microscopically positive (Blood film) camels have hard ticks at different sites of animal body particularly genital system, as shown in photo no. (9). Hard ticks may play an outstanding role in spread of Trypanosoma evansi infection.

Regarding the Prevalence of Trypanosoma evansi infection of the examined camels by thin blood smear. Out of 396 examined camels, 189 (47.73\%) cases showed clinical abnormalities and the remained cases $\mathbf{( 5 2 . 2 7 \%}$ ) appeared to be clinically healthy. Blood samples of all camels with clinical abnormalities were microscopically examined for detection of Trypanosoma evansi infection and found that $23(\mathbf{1 2 . 1 7 \%})$ cases were harbored infection. The remained cases $(\mathbf{n}=\mathbf{1 6 6}, \mathbf{8 7 . 8 3 \%})$ were trypanosoma free by using blood film procedures. On the other hand, all clinically healthy cases $(\mathbf{n}=207)$ of the examined camels $(\mathbf{n}=\mathbf{3 9 6})$ were subjected to blood film technique and they were trypanosoma free.

Approximately, $\mathbf{7 5 . 3 0 \%} \quad(\mathbf{n}=\mathbf{1 2 5}) \quad$ of the clinically suspected cases with negative results of blood film examination were subjected to molecular detection of Trypanosoma evansi infection using PCR based TBR $1 / 2$ primer. It was found that $\mathbf{6 0} \mathbf{( 4 8 \% )}$ were positive as shown in photo no. (11), and 65 (52\%) were negative to Trypanosoma evansi infection. Twenty five cases of the clinically healthy were randomly selected and subjected to PCR procedure. It was found that $\mathbf{5} \mathbf{( 2 0 \% )}$ cases were positive and $\mathbf{2 0}(\mathbf{8 0} \%)$ cases were negative to Trypanosomaevansi infection.

On the current work the prevalence of Trypanosoma evansi infection using blood film technique was $\mathbf{5 . 8 1 \%}$ of all tested camels (12.17\% among clinically suspected camels). Whereas, the prevalence of Trypanosoma evansi infection using TBR 1/2 primer-based PCR was jumped up to $\mathbf{4 3 . 3 \%}$ of all examined camels $\mathbf{4 8 \%}$ among clinically suspected camels and $\mathbf{2 0 \%}$ among apparently healthy camels). This may indicate that every case shows positive to infection by blood film technique opposites $\mathbf{7 . 5}$ cases positive to infection by TBR $1 / 2$ primerbased PCR technique (1:7.5). 
Table 1: The number of samples in relation to clinical state of examined camels:

$\begin{array}{lll}\text { Clinically suspected } & \text { clinically healthy } & \text { Total }\end{array}$

\begin{tabular}{lccccc}
\hline & $\%$ & & & & \\
Number & & Number & & Number & \\
\hline 189 & $47.73 \%$ & 207 & $52.27 \%$ & 396 & $100 \%$ \\
\hline
\end{tabular}

Table 2: Prevalence of Trypanosoma evansi infection of the examined camels by thin blood smear:

\begin{tabular}{|c|c|c|c|c|c|}
\hline \multirow{2}{*}{ Camels } & \multirow{2}{*}{$\begin{array}{c}\text { No. of } \\
\text { examined } \\
\text { camels }\end{array}$} & \multicolumn{2}{|c|}{ Positive results } & \multicolumn{2}{|c|}{ Negative results } \\
\hline & & No. & $\%$ & No. & $\%$ \\
\hline Clinically suspected & 189 & 23 & $12.17 \%$ & $166^{*}$ & $87.83 \%$ \\
\hline Apparently healthy & 207 & $\mathbf{0}$ & $0 \%$ & $207 * *$ & $100 \%$ \\
\hline Total & 396 & 23 & $5.81 \%$ & 373 & $94.19 \%$ \\
\hline
\end{tabular}

*166 representing clinically suspected and hematologically negative cases.

**207 representingclinically healthy and hematologically negativecases

Table 3: Prevalence of Trypanosoma evansi infection by PCR:

\begin{tabular}{|c|c|c|c|c|c|}
\hline \multirow{2}{*}{ Camels } & \multirow{2}{*}{ No. of camels } & \multicolumn{2}{|c|}{ Positive results } & \multicolumn{2}{|c|}{ Negative results } \\
\hline & & No. & $\%$ & No. & $\%$ \\
\hline Clinically suspected & $125^{*}$ & 60 & $48 \%$ & 65 & $52 \%$ \\
\hline Apparently healthy & $25 * *$ & 5 & $20 \%$ & 20 & $80 \%$ \\
\hline Total & 150 & 65 & $43.3 \%$ & 85 & $56.7 \%$ \\
\hline
\end{tabular}

*125 representing $\mathbf{7 5 . 3 0} \%$ of the clinically suspected cases and hematologically negative Cases $(\mathbf{n}=\mathbf{1 6 6})$. **25 representing $\mathbf{1 2 . 0 8} \%$ of clinically healthy and hematologically negative $(\mathbf{n}=\mathbf{2 0 7})$. 


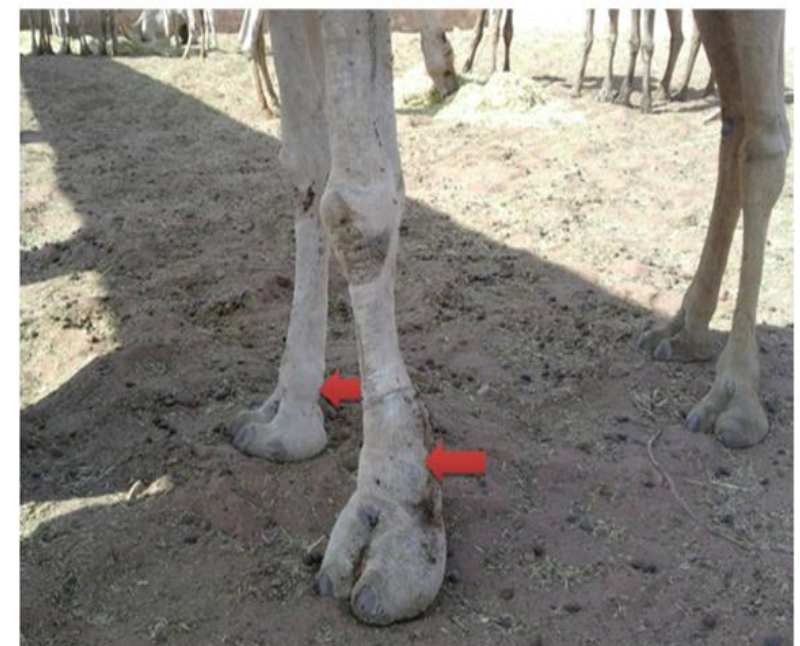

Photo no (1): Edematous swelling in the lower parts of legs of camel infected with Trypanosoma evansi infection

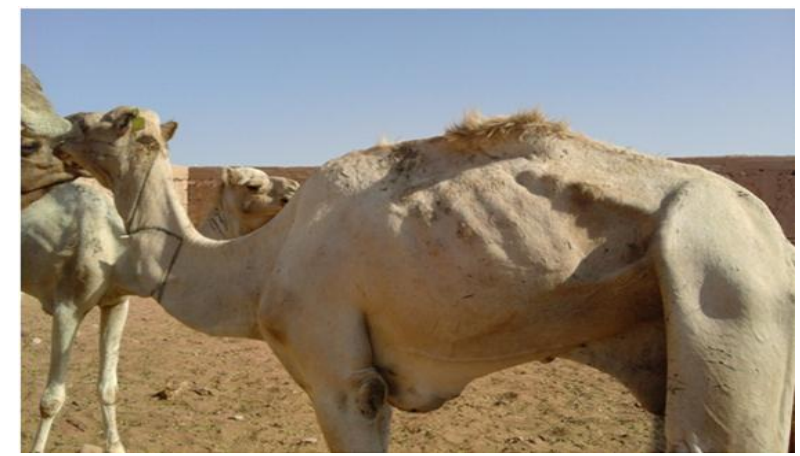

Photo no (3): Gelatinous mass of the hump \& the hump was bent to left side in camel infected with Trypanosoma evansi
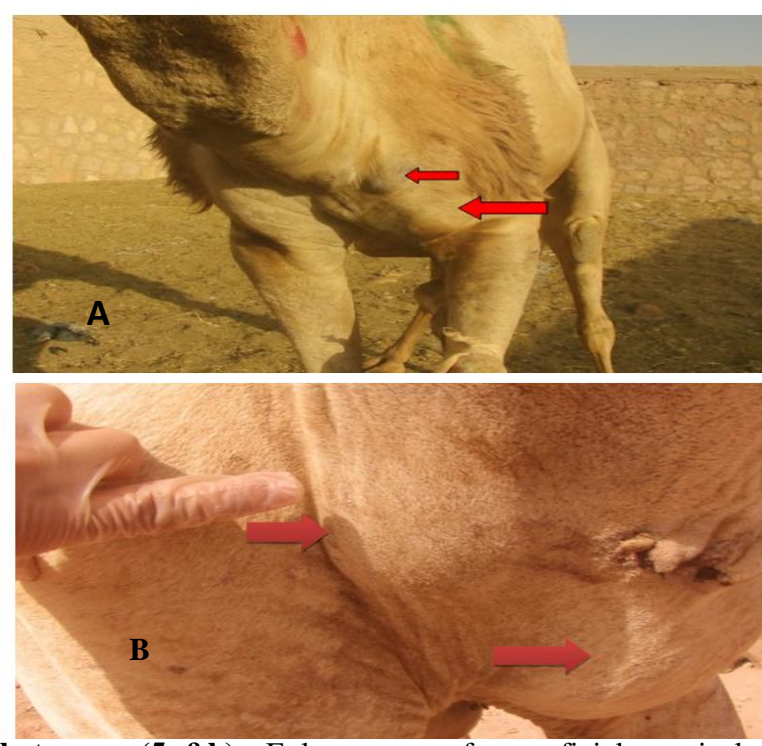

Photo no. (5a\&b): Enlargement of superficial cervical lymph nodes at the base of the neck surrounded by wide edematous area extended to the upper areas of the forelimb in camels infected with Trypanosoma evansi.
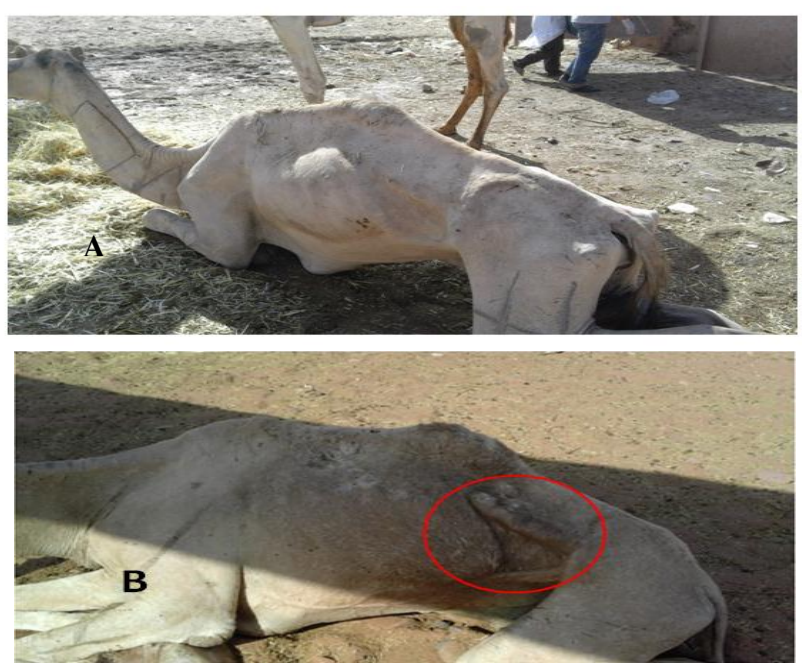

Photo no (2 a \& b): Severe emaciation, disapperance of the hump and projection of the ribs in camel infected with Trypanosoma evansi.

Note the sloughing hairy coat of the hump and characteristics depth of the flank region during standing postion

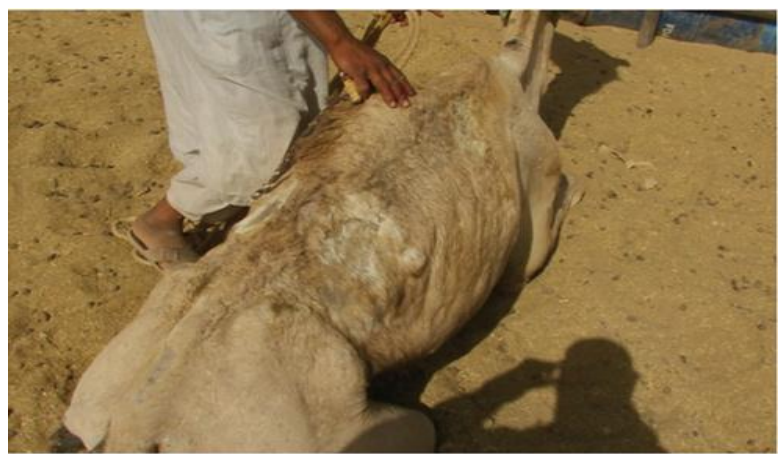

Photo no (4): Harsh and scurfy skin in camel infected with Trypanosoma evansi

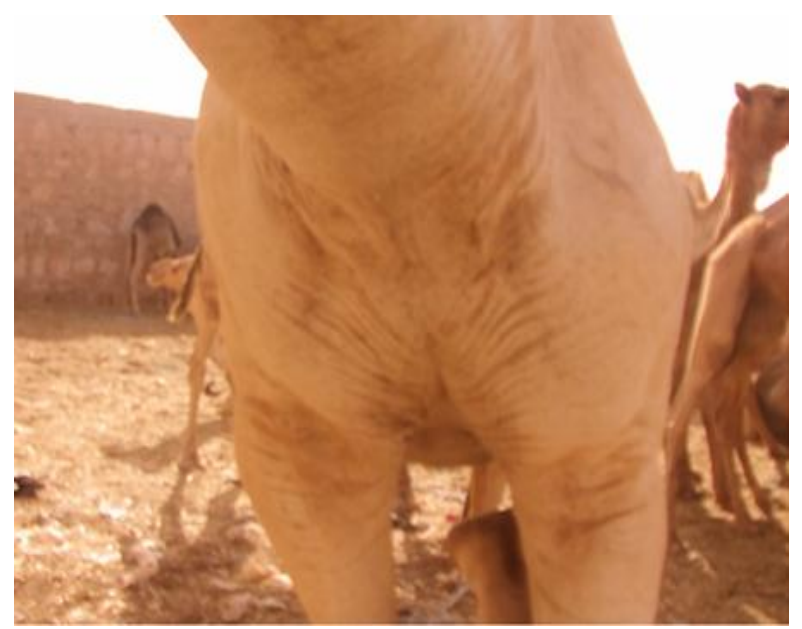

Photo no. (6): Edematous swelling in the base of neck in camels infected with Trypanosoma evansi. 


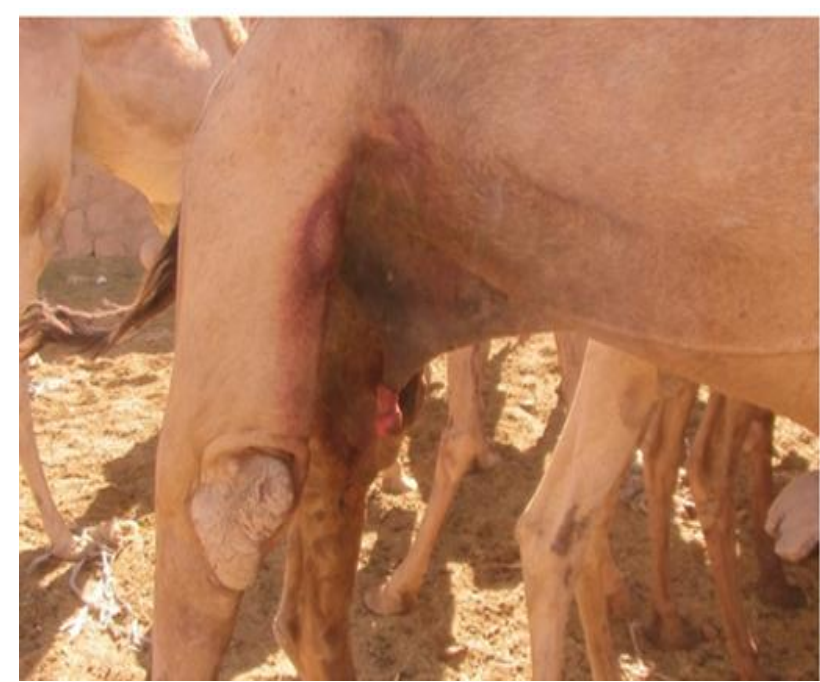

Photo no. (7): Edematous Prolapsed Penis was an obvious signs of camel infected with Trypanosoma evansi.

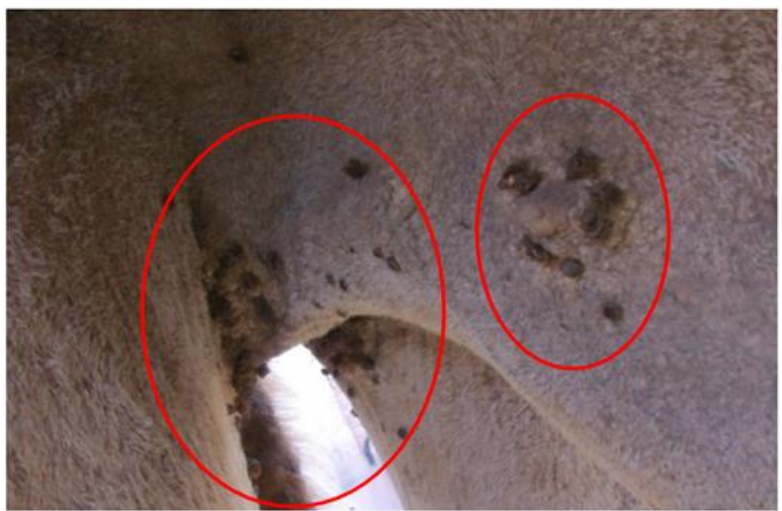

Photo no. (9): Numerous ticks in camel infected with Trypanosoma evansi.

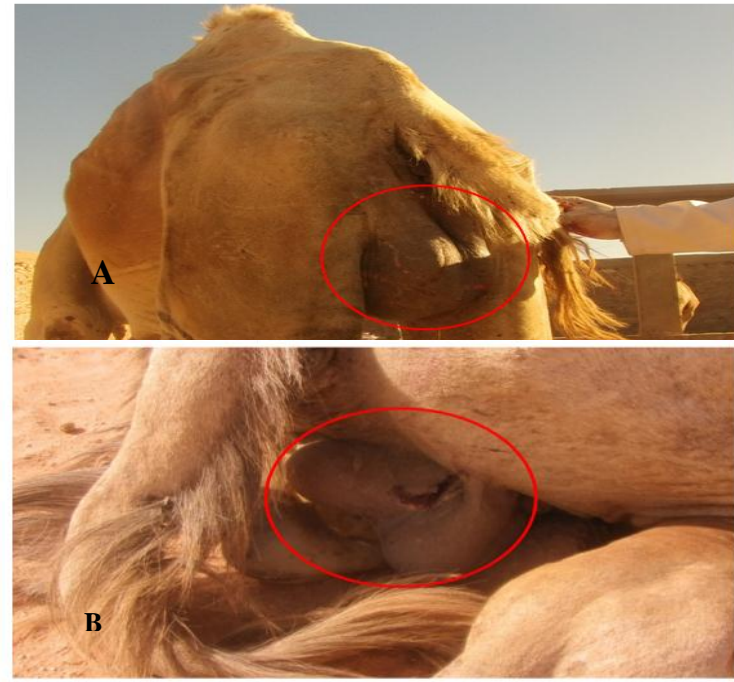

Photo no (8a\&b): Edematous swelling in the scrotal sacs and testicles were enlarged in camels infected with Trypanosoma evansi. The blood film was microfilaria free.

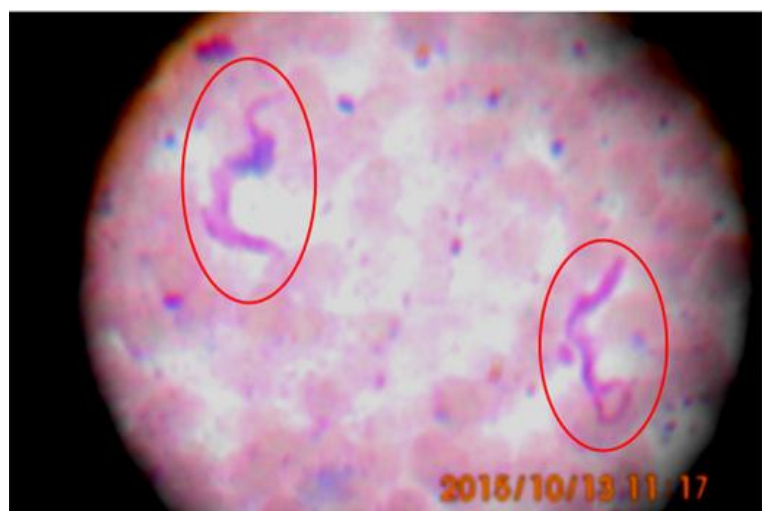

Photo no. (10): Blood film stained with Giemsa stain Trypanosoma evansi (X100). 


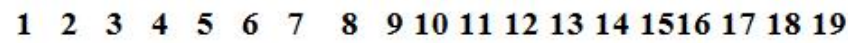

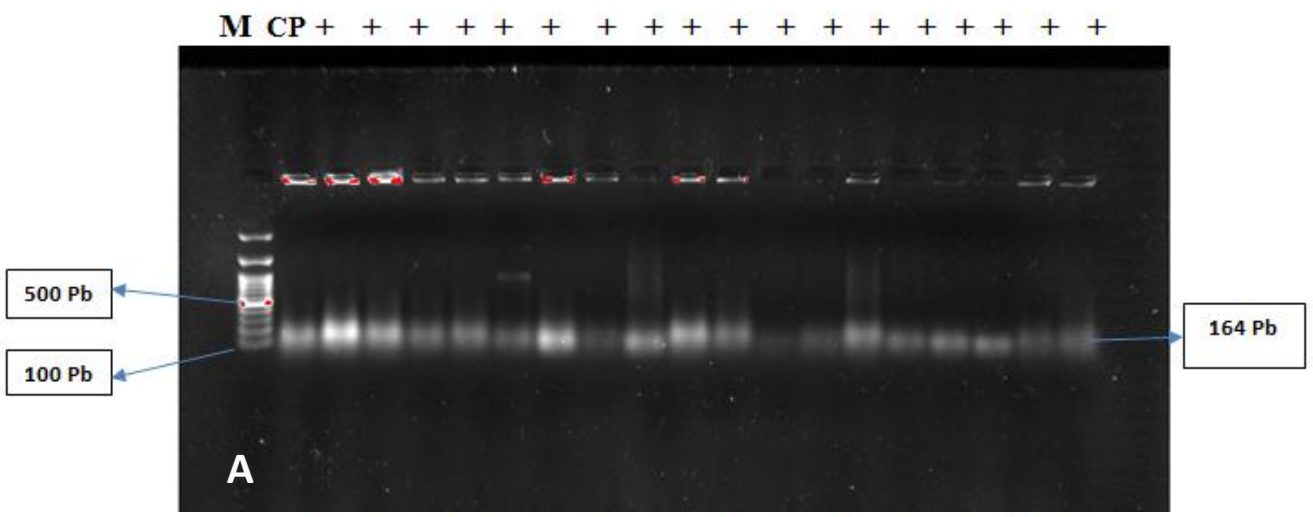

$\begin{array}{llllllllllllll}1 & 2 & 3 & 4 & 5 & 6 & 7 & 8 & 9 & 10 & 11 & 12 & 13 & 14\end{array}$

$\mathrm{M} \mathrm{CN}-+++++++++++$

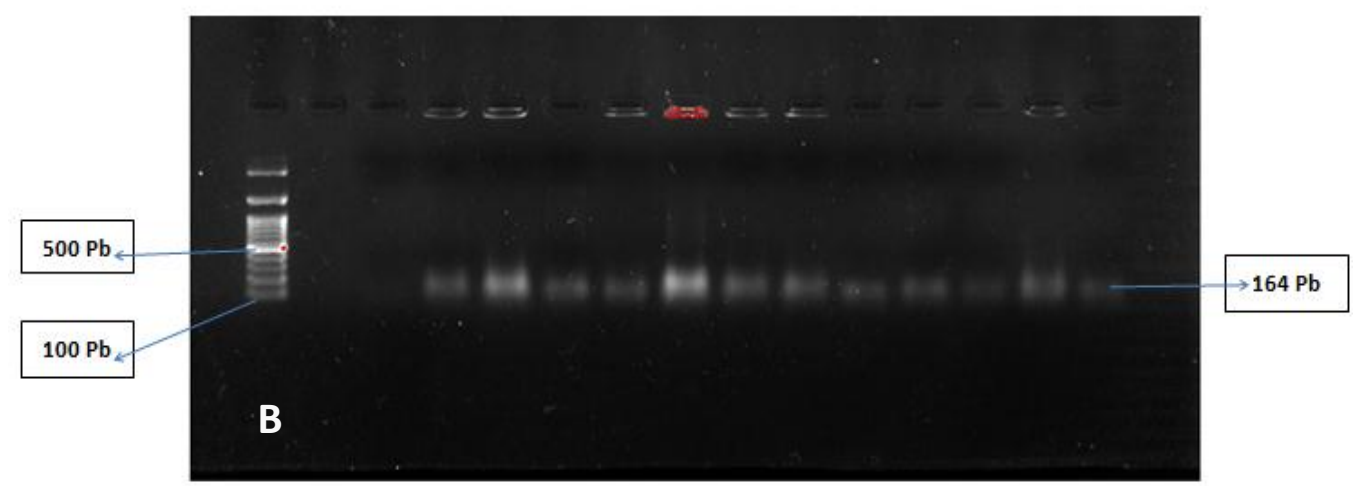

Photo no (11a\&b): Agarose (1.5\%) gel electrophoresis of PCR product in camel infected with Trypanosoma evansi.
$(\mathbf{M})$ = marker,
$(\mathrm{CP})=$ control positive
$(\mathrm{CN})=$ control negative
$(+)=$ positive,$\quad(-)=$ negative

*N.B: the control positive: positive blood sample with Trypanosoma evansi by wet mount technique \& confirmed by thin blood smear.

\section{DISCUSSION}

Exportation of camels is one of important economic resources for many African countries where camels were present in large numbers, Egypt import camels from different African countries mainly Sudan. Trypanosomiasis, Pulmonary hydatiosis and gastroin test in alnematodiasis appears to be the most common endoparasitic diseases of camels in Upper Egypt Abdel-Rady, (2014). Trypanosoma evansi was regarded as a major constrain for Camel health and productivity in all camel rearing areas of the World Atarhouch, (2003). Procedures including diagnosis, curative or preventive treatment and quarantine should be established to insure the status of the camels moving from one country to another.

Concerning the observed clinical signs on trypanosomes infected camels in the current study. Trypanosoma evansi occurred in chronic and acute forms. The chronic form of the disease was the most common. Similar previous results were reported by (Gutierrez et al., 2000 and Njiru et al., 2004). Signs of acute form of Trypanosoma evansi infection were poor general condition. Trypanosoma evansi by itself was one of the major causes resulting in poor body condition Röttcher et al. (1987). On the other hand, camels with poor body conditions were more likely to be positive in Giemsa stained thin smear compared to those with good body condition.

Regarding to the morning rectal temperature of the infected camels, there were rising of body temperature up to $\left(38.81 \pm 0.05^{\circ} \mathrm{C}\right)$, it was higher than that recorded for the healthy animals $\left(36.71 \pm 0.05^{\circ} \mathrm{C}\right)$. Higher elevation of body temperature is associated with parasitaemia which is an important sign of camels infected with Trypanosoma evansi Tehseen et al. (2015). 
Edematous swellings in $34.78 \%$ of camels infected with Trypanosoma evansi occur in the lower parts of legs, scrotal sacs and testicles and in the base of neck. Similar results were reported by Higgins, (1983) who reported that edema may develop along the neck and abdomen, Kaufmann et al. (1996) recorded edema of the feet, brisket, under belly and eyelids, Mottelib et al. (2005) stated that edematous swelling at some parts of the body especially hind limbs. Abdel-Rady, (2008) reported edematous swelling in testicles. Trypanosoma evansi was more virulent and devastating in its effect on reproductive performance of dromedary bulls due to formation and precipitation of immune complexes at the site of junctional complexes of the seminiferous tubules, pituitary dysfunction and testicular degeneration leading to infertility and sterility Al-Qarawi et al. (2004). About $13.04 \%$ of camels infected with Trypanosoma evansi showed edematous with Prolapsed Penis with disappearance of the characteristic hook shaped tip of the penis; These signs could be attributed to the chronic form of Trypanosoma evansi infection was likely to be associated with secondary infection due to immuno-suppression Tekle and Abebe (2001). Signs of chronic form of Trypanosoma evansi infection were general debility, severe emaciation, pale mucous membrane of conjunctiva, disappearance of the hump, projection of the ribs atrophy of the thigh muscles, the skin was harsh and scurfy, enlargement of lymph nodes and lacrimation. Similar signs were reported by (KohlerRollefson et al., 2001; Getachew, 2005; Saleh et al., 2009 and Tehseen et al., 2015).

Approximately $33 \% \quad(34.78 \%) \quad$ (Microscopically positive and clinically suspected camels) had hard ticks at different sites of camel's body particularly genital system. Ticks may play a role in transmission of Trypanosoma evansi Uilenberg, (1995). Higgins (1983) concluded that camels infected with Trypanosoma evansi were highly susceptible to ectoparasites such as mange and ticks.

On current study, the prevalence of Trypanosoma evansi infection among the examined camels with clinical abnormalities was $12.17 \%$. However, the overall prevalence was $5.81 \%$, the low percent of prevalence rate by thin blood smear may attribute to the chronic nature of the disease. In chronic phase of Trypanosoma evansi, there was a tendency for the parasite to invade the tissues, which may lead to either scanty or totally absent of Trypanosoma evansi in the blood of infected camels Chaudhri et al. (1996). Furthermore, in chronic infection, parasitaemia is very low; therefore, diagnosis of Trypanosoma evansi by thin blood smear is easily procedure, cheap and useful in acute stage of the disease; but it is insufficient in chronic stage Pathak et al. (1997).

The prevalence rate $(5.81 \%)$ by thin blood smear was coincided with the previous results of (El-Sawalhey and Ebeid 1994), Abu-Zeid, (2003), Mottelib et al. (2005) and Zayed et al. (2010). They reported that prevalence of Trypanosoma evansi in Egypt was 5\%, 5.82\%, $5.82 \%$, 5.67\%, respectively, and, $5.3 \%$ (Delafosse and Doutoum, 2004) in Chad, 6\% (Ibrahim, (2008) in Sudan and 5.15\% Aregawi et al. (2015) in Ethiopia. On the other hand, the present prevalence rate was lower than previous results of Mahran (2004) and Elhaig et al. (2013), they reported that prevalence of Trypanosoma evansi in Egypt was $11.5 \%$ and $12 \% \%$, respectively, and $13.3 \%$ El-Amin, (1997) in Western Sudan, $12.12 \%$ Hagos et al. (2009) in Ethiopia and $14 \%$ Bennoune et al. (2013) in Algeria. Moreover, the results in the present study were higher than previous reports of Abdel-Rady, (2008) and Abd Elmaleck et al. (2014) who concluded that the prevalence of the disease in Egypt was $4.1 \%$ and $3.06 \%$, respectively, and $1.3 \%$ Dia et al. (1997) in Mauritania, 2.3\% Ngaira et al. (2002) in Kenya, $2 \%$ Fikru et al. (2015) in Ethiopia. The results in the present study were higher than previous reports may attribute to drug-resistant infections of Trypanosoma evansi Zhang et al. (1993), Ng'ayo et al. (2005) and Salim et al. (2011).

The variation in prevalence rate of Trypanosoma evansi may attributed to the fact that trypanosoma parasites circulate within a wide and diverse host community, number of the examined camels, variations in the density of mechanical vectors, movements of camels from area to area increase the risk of infection, local herd management system and control interventions practiced by competent authorities.

In Egypt, Mahmoud et al. (2008); Barghash et al. (2014) and El-Hewairy et al. (2014) indicated prevalence rates of Trypanosoma evansi by thin blood smears about $27.6 \%$, $20.9 \%$ and $16.9 \%$, respectively. Their results were higher than the present results. This may attributed to the occurrence of high levels of newly and active infections, the close contact of camels with other carrier animals, such as sheep and goats act as a serious source of infection and transmission.

PCR detection of Trypanosoma evansi has known a great expansion during the last 20 
years, but primer sets are often insufficiently assessed and compared Pruvot et al. (2010). PCR detected acute and chronic animals and the following of drug treated case. TBR $1 / 2$ that amplified 164 bp DNA fragment provided valuable tools to study the epidemiology of Trypanosoma evansi infection in camels' population in Egypt Ashour et al. (2013). Currently, PCR depends on identifying portions (base pairs) of DNA, from the nucleus or from the kinetoplast, which are specific for Trypanosoma evansi. The target sequences for TBR1 \&TBR2 found in nucleus not in kinetoplast making results independent of the parasite kinetoplastic state and avoid the problem of failure targeting kDNA as reported by Gonzales et al. (2003). Pruvot et al. (2010) indicated that TBR primers showed the highest sensitivity and specificity for the detection of Trypanosoma evansi and were able to detect $0.01 \mathrm{pg}$ of purified Trypanosoma evansi DNA and a parasitemia below one parasite per $\mathrm{ml}$ of blood without false positive reactions of samples tested. The high detection capacity of TBR primers was attributed to highly repeated sequences.

The prevalence of Trypanosoma evansi in the present study by TBR $1 / 2$ primer-based PCR revealed that Trypanosoma evansi infection was $43.3 \%$. Higher prevalence of Trypanosoma evansi detected by PCR may attribute to the higher sensitivity of the molecular technique. This result was in agreement with Elhaig et al. (2013) who reported that the prevalence of clinical and sub-clinical Trypanosoma evansi infection among camels in Egypt was $46 \%$ by TBR $1 / 2$ primer-based PCR technique. On the other hand, the result recorded in the present study were higher than result of Tehseen et al. (2015) who indicated that the prevalence of Trypanosoma evansi infection among 1005 dromedary camels in Pakistan about $31.9 \%$ with TBR $1 / 2$ primer-based PCR. Moreover, the obtained result was lower than result of Barghash et al. (2014) who reported that the prevalence rate of Trypanosoma evansi infection of 249 camels in Northern-West Coast, Egypt was $74.7 \%$ with TBR $1 / 2$ primer-based PCR. These variations in the prevalence rate may be attributed to geographic and climatic conditions. The obtained result of PCR indicate high proportion of sub-clinical infection of Trypanosoma evansi among the investigated camels and this result is in agreement with the findings of Mahran, (2004) and Elhaig et al. (2013).

Interestingly, on the current work the prevalence of Trypanosoma evansi infection using blood film technique was $5.81 \%$ of all tested camels $(12.17 \%$ among clinically suspected camels). Whereas, the prevalence of Trypanosoma evansi infection using TBR 1/2 primer-based PCR was reached to $43.3 \%$ including $(48 \%$ among clinically suspected camels and $20 \%$ among apparently healthy camels). This may indicate that every case shows positive to infection by blood film technique opposites 7.5 cases positive to infection by TBR $1 / 2$ primer-based PCR technique (1:7.5). This may indicate high sensitivity of TBR $1 / 2$ primer-based PCR technique than thin blood smear. Many clinically suspected camels were negative by thin blood smear examination and found to be positive by TBR $1 / 2$ primer-based PCR technique which may indicate high proportion of sub-clinical infection of Trypanosoma evansi among the investigated camels, Approximately $20 \%$ of apparently healthy camels were positive by TBR $1 / 2$ primer-based PCR and negative by blood film technique referring to the carrier state of Trypanosoma evansi infection in camels imported from Sudan.

The results obtained by Delafosse and Doutoum (2004) and Ibrahim, (2008) indicated that the proportion between thin blood technique and PCR technique was $1: 13$ and $1: 11$, respectively. The most microscopic techniques are poorly sensitive and Giemsa stained thin smear examination revealing the lower detection limit is greater than 500,000 trypanosomes $/ \mathrm{ml}$ of blood (OIE, 2012). Furthermore, it was reported that the detection of less than $2.5 \times 106$ trypanosomes per $\mathrm{ml}$ in blood samples by microscopy is not functional Desquesnes, (2004). In contrast, PCR based assay is a highly sensitive and specific for the detection of $\mathrm{T}$ evansi present in the blood of different animals and vector Abdel-Rady, (2008) and Baticados et al. (2011).

\section{CONCLUSION}

The obtained results in the present study indicate the spread of Trypanosoma evansi infection among camel population imported from Sudan. Consequently, it is recommended that good management and hygienic precautions should be carried out immediately to minimize the entrance of infectious diseases from Sudan to Egypt, establish a modern laboratory unit containing PCR in Abu-Simbel Veterinary Quarantine for camel diseases to reveal up the infectious diseases among camels and other animals. 


\section{REFERENCES}

Abd El-Rady, A. (2008): Epidemiological studies (parasitological, serological and molecular techniques) of Trypanosoma evansi infection in camels (Camelusdromedarius) in Egypt, Veterinary World; 1(11): 325328.

Abd El-Rady, A. (2014): Epidemiological studies on parasitic infestations in camels (Camelus dromedaries) IN EGYPT. European Journal of Environmental Ecology; 1(1):16-20.

Abd-Elmaleck, B.; Abed, G.H. and Mandour, A.M. (2014): Some protozoan parasites infecting blood of camels (Camelusdromedarius) at Assiut Locality, Upper Egypt. J. Bacteriol. Parasitol.; 5(2): 1- 6.

Abu-Zeid, A. (2003): Epizootiological studies on trypanosomiasis in camels. Ph. D. (Infectious diseases) Faculty of Vet. Med. Cairo University. Benisuef Branch. Egypt.

Al-Qarawi, A.A.; Omar, H.M.; Abdel-Rahman, H.A.; El-Mougy, S.A. and El-Belely, M.S. (2004): $\quad$ Trypanosomiasis-induced infertility in dromedary (Camelusdromedarius) bulls: changes in plasma steroids concentration and semen characteristics. Animal reproduction science, 84(1): 73-82.

Aregawi, W.G.; Kassa, S.T.; Tarekegn, K.D.; Brehanu, W.T.; Haile, S.T. and Kiflewahid, F.Z. (2015): Parasitological and Serological study of camel trypanosomosis (surra) and associated risk factors in Gabi Rasu Zone, Afar, Ethiopia. Journal of Veterinary Medicine and Animal Health, 7 (6): 234- 240.

Ashour, A.A.; El-Naga, T.R.A.; Barghash, S.M. and Salama, M.S. (2013): Trypanosoma evansi: Detection of Trypanosoma evansi DNA in naturally and experimentally infected animals using TBR 1 \& TBR 2 primers. Experimental parasitology, 134(1): 109-114.

Atarhouch, T.; Rami, M.; Bendahman, M.N. and Dakkak, A. (2003): Camel trypanosomosis in Morocco 1: results of a first epidemiological survey. Veterinary Parasitology, 111: 277-286.

Barghash, S.M.; El-Naga, T.R.A.; El-Sherbeny, E.A. and Darwish, A.M. (2014): Prevalence of Trypanosoma evansi in Maghrabi Camels (Camelusdromedarius) in Northern-West Coast, Egypt using Molecular and Parasitological Methods, Acta Parasitologica Globalis, 5 (2): 125132.
Baticados, W.N.; Fernandez, C.P. and Baticados, A.M. (2011): Molecular detection of Trypanosoma evansi in cattle from quirino province, Philippines, Veterinarski Archive, 81(5): 635-646.

Bennoune, O.; Adili, N.; Amri, K.; Bennecib, L. and Ayachi, A. (2013): Trypanosomiasis of camels (Camelusdromedarius) in Algeria: First report. In Veterinary research forum: An international quarterly journal. 4 (4): 273-275.

Chaudhri, S.S.; Gupta, R.P. and Singh, V. (1996): Experimental trypanosomiasis in cross breed calves; its diagnosis and chemoprophylaxis. J. Anim. Sci., 66:662665.

Delafosse, A. and Doutoum, A.A. (2004): Prevalence of Trypanosoma evansi infection and associated risk factors in camels in eastern Chad. Veterinary parasitology, 119(2): 155-164.

Desquesnes, $\quad$ M. (2004): $\quad$ Livestock trypanosomosis cooperation internationale en rechercheagronomique pour le dévelopement (CIRAD)/ Élevageet médecin evétérinairetropicale World Organization for Animal Health (OIE). Paris, France. 118.

Desquesnes, M.; McLaughlin. G.; Zoungrana, A. and Davila, A.M. (2001): Detection and identification of Trypanosoma of African livestock through a single PCR based on internal transcribed spacer 1 of rDNA. International Journal of Parasitology, 31: (5-6):609-13.

Dia, M.L.; Diop, C.; Aminetou, M.; Jacquiet, P. and Thiam, A. (1997): Some factors affecting the prevalence of Trypanosoma evansi in camels in Mauritania. Vet. Parasitol, 72: 111-120.

El-Amin, I.H.R. (1997): Some Epidemiological Studies on Drug Resistant Trypanosoma evansi Isolated from Sudan. Ph. D., Veterinary Science, University of Khartoum.

Elhaig, M.M.; Youssef, A.I. and El-Gayar, A.K. (2013): Molecular and Parasitological detection of Trypanosoma evansi in camels in Ismailia, Egypt, Veterinary parasitology, 198(1): 214-218.

El-Hewairy, H.M.; Galal, S.A. and Mousa, W.M. (2014): New approach for diagnosis of Trypanosomes evansi in camel (Camelus dromedaries) by ELISA, Life Sci. J. 2014, 11(10): 1258-1263.

El-Said, H.M.; Natulya, V.M and Hilali, M. (1998): Diagnosis of Trypanosoma evansi infection among Sudanese camels imported to Egypt using card agglutination test (CATT) and antigen detection latex agglutination test 
(Suratex). The J. Protozool. Res., 8(3): 194- 200

El-Sawalhey, A.A. and Ebeid, M.H (1994): Evaluation of different methods of diagnosis for camel trypanosomiasis, Beni-Suef. Vet. Med. Res. Vol IV, 1(1): 70-79.

FAO (2000): FAO production Year Book, Vol. 54: Food and Agriculture Organization of United Nations, Rome, Italy.

Fikru, R.; Andualem, Y.; Getachew, T.; Menten, J.; Hasker, E.; Merga, B. and Büscher, P. (2015): Trypanosome infection in dromedary camels in Eastern Ethiopia: prevalence, relative performance of diagnostic tools and host related risk factors, Veterinary Parasitology. 211(3-4): 175-181.

Getachew, A. (2005): $\quad$ Epidemiological distribution and prevalence of camel trypanosomosis and within the vector control methods in Ethiopia. MVSC Thesis, AAU. Faculty of Veterinary Medicine, Debre Zeit.

Gonzales, J.L.; Jones, T.W.; Picozzi, K. and Cuellar, H.R. (2003): Evaluation of a polymerase chain reaction assay for the diagnosis of bovine trypanosomiasis and epidemiological surveillance in Bolivia. Kinetoplastid Biology and Disease, 2: 8 .

Gutierrez, C.; Juste, C.; Corbera, J.A.; Magnus, E.; Verloo, D. and Montoya, J.A. (2000): Camel trypanosomosis in the Canary Islands: assessment of sero prevalence and infection rates using the card agglutination test (CATT/T. evansi) and parasite detection tests. Vet Parasitol. 90:155-159.

Hagos, A.; Yilkal, A.; Esayass, T.; Alemu1, T.; Fikru, R.; Feseha, G. Goddeeris, B.M. and Claes, F. (2009): Parasitological and Serological survey on trypanosomis (surra) in camels in dry and wet areas of Bale Zone, Oromyia Region. Ethiopia. Revue Méd. Vét, 160 (12): 569-573.

Higgins, A.J. (1983): Observations on the diseases of the Arabian camel (Camelusdromedarius) and their control. A review. Veterinary Bulletin (UK), 53 (12):1089-1098

Ibrahim, H. (2008): Molecular Diagnosis of Trypanosoma evansi infection in Camels from Gedariff and Kordofan States of the Sudan. M.Sc. Thesis. Department of Parasitology. Faculty of Veterinary Medicine. University of Khartoum.

Inoue, N.; Honzako, Y.; Hirumi, K.; Xuan, X.; Agatsuma, T.; Nagasawa, H.; Mikami, T. and Hirumi, H. (1998): Kinetoplast DNA and procyclic acidic repetitive protein Aalpha gene of Trypanosoma evansi. Research 8, 28-43.
Kaufmann, M.L.; Meirvenne, N.V.; Magnus, E.; Delarue, M.L.; Decarli, G.A.; Herrer, H.M.; Luckins, A.G.; Diop, C.; Thiam, A.; Jacqiet, A. and Harmers, D. (1996): Evaluation of four diagnosis test, blood smears CATT, IFAT and ELISA-Ag in study of the epidemiology of T.evansi camel trypanosomosis in Mauritania, Revue and Elev. Med vet. Pays Trop, 47: 129-136.

Kohler-Rollefson, I.; Mundy, P. and Mathias, E. (2001): A field manual of camel diseases. Traditional and modern healthcare for the dromedary. ITDG Publication.

Mahmoud, A.M.; Amin, M.M.; Youssef, R.R.; ElKattan, A.; Goda, S.A. and Abou El-Naga, T.R. (2008): Studies on some endoparasites of camels in the south eastern area of Egypt, SCVMJ, XIII, (1): 81- 92.

Mahony, J.B.; Chango, S.; Coombes, B.K.; Smieja, M. and Petrich, A. (2000): Analytical sensitivity, reproducibility of results and clinical performance of five PCR assays for detecting chlamydia pneumonia DNA in peripheral blood mononuclear cells. J. Clinic. Micr, 26: 22 $-27$.

Mahran, O.M. (2004): Some studies on blood parasites in camels (Camelusdromedarius) at Shalatin city, Red sea governorate. Assiut Vet. Med. J., 50 (102):172-184.

Masiga, D.K.; Smyth, A.J.; Hayes, P.; Bromidge, T.J. and Gibson, W.C. (1992): Sensitive detection of trypanosomes in tsetse flies by DNA amplification. Int. J. Parasitol. 22: 909-918.

Mottelib, A.A.; Hosein, H.I.; Mourad, I.; ElSherif, A.M. and Abo-Zeid, A.S.I. (2005): Comparative evaluation of various diagnostic techniques for Trypanosoma evansi in naturally infected camels. ISAH - Warsaw, Poland, 2(6): 505-507

Muieed, M.A.; Chaudhary, Z.I. and Shakoor, A.R. (2010): Comparative studies on the sensitivity of polymerase chain reaction (PCR) and microscopic examination for the detection of Trypanosoma evansi in horses. Turk. J. Vet. Anim. Sci. 34, 507-512.

Ngaira, J.M.; Bett, B. and Karanja, S.M. (2002): Animal-level factors for Trypanosoma evansi infection in camels in eastern and central parts of Kenya. Onderst. Vet. Res. 69: 263-271.

Ng'ayo, O.M.; Njiru, Z.K.; Kenya, U.E.; Muluvi, M.; Osir, O.E. and Masiga, D.K. (2005): Detection of trypanosomes in small ruminants and pigs in western Kenya: important reservoirs in the epidemiology of sleeping sickness? Kinetoplastid Biology and Disease, 4:5. 
Njiru, Z.K.; Constantine, C.C.; Ndung'u, J.M.; Robertson, I.; Okaye, S.; Thompson, R.C.A. and Reid, S.A. (2004): Detection of Trypanosoma evansi in camels using PCR and CATT/T. evansi tests in Kenya. Veterinary parasitology, 124(3): 187-199.

Obihiro (1998): Proceedings of RCPMIObihiro/OIE Paris International Symposium on Strategies for Research and Control of Surra Trypanosoma evansi infection. J. Protozool. Res. 8:1-15.

OIE (2012): Manual of diagnostic tests and vaccines for terrestrial animals. http:// www.oie.int/fileadmin/Home/eng/Health standards/tahm/2.04.18_TRYPANOSOM OSIS

Pathak, K.M.L.; Singh, Y.; Meirvenne, N.V. and Kapoor, M. (1997): Evaluation of various diagnostic techniques for Trypanosoma evansi infections in naturally infected Camels. Vet. Parasitol. 69: 1-2.

Pruvot, M.; Kamyingkird, K.; Desquesnes, M.; Sarataphan, $N$. and Jittapalapong, $S$. (2010): A comparison of six primer sets for detection of Trypanosoma evansi by polymerase chain reaction in rodents and Thai livestock. Veterinary parasitology, 171(3): 185-193.

Röttcher, D.; Schillinger, D. and Zweygarth, E. (1987): Trypanosomiasis in the camel (Camelusdromedarius). 430 Rev. Sci. Tech. Off. Int. Epizoot. 6: 463-470.

Saleh, M.A.; Al-Salahy, M.B. and Sanousi, S.A. (2009): Oxidative stress in blood of camels (Camelus dromedaries) naturally infected with Trypanosoma evansi. Veterinary parasitology, 162(3): 192-199.

Salim, B.; Bakheit, M.A.; Kamau, J.; Nakamura, I. and Sugimoto, C. (2011): Molecular epidemiology of camel trypanosomiasis based on ITS1 rDNA and RoTat 1.2 VSG genes in the Sudan. BioMed Central Ltd, Parasites \& Vectors, 4:31.

Sengupta, P.P.; Balumahendirana, M.; Suryanaryanab, W.; Raghaven- dra, A.G.; Shomea, B.R.; Gajendragada, M.R. and Prabhudas, K. (2010): PCR-based diagnosis of surra-targeting VSG gene: Experimental studies in small laboratory rodents and buffalo. Vet. Parasitol. 171, 22-31

Tehseen, S.; Jahan, N.; Qamar, M.F.; Desquesnes, M.; Shahzad, M.I.; Deborggraeve, S. and Büscher, P. (2015): Parasitological, serological and molecular survey of Trypanosoma evansi infection in dromedary camels from Cholistan desert. Pakistan. Parasites \& Vectors, 8(1): 1-11.

Tekle, T. and Abebe, G. (2001): Trypanosomosis and Helminthoses: Major Health Problems of Camels (Camelus dromedaries) in the Southern Rangelands of Borena, Ethiopia. J. Camel Pra. Res. 8(1):39-42.

Tizard, I.R.; Nielsen, K.R.; Seed, J.R. and Hall, J.E. (1979): Biologically active products from African trypanosomes. Microbial. Rev., 42: 661-681.

Uilenberg, G. (1995): International collaborative research: significance of tick- borne hemoparasitic diseases to world animal health. Veterinary Parasitology; 57: 1941.

Ventura, R.M.; Takata, C.S.A.; Silva, R.A.M.S.; Nunes, V.L.; Takeda, G.F. and Teixeira, M.M.G. (2000): Molecular and morphological studies of Brazilian Trypanosomaevansi stocks, the total absence of kDNA in trypanosomes from both laboratory stocks and naturally infected domestic and wild mammals. Parasitology 86:1289-1298.

Zayed, A.A.; Habeeb, S.M.; Allam, N.A.T.; Ashry, H.M.Z.; Mohamed, A.H.M.; Ashour, A.A. and Taha, H.A. (2010): A critical comparative study of parasitological and serological differential diagnostic methods of Trypanosoma evansi infections in some farm animals in Egypt. Am. Eurasian J. Agr. Environ. Sci., 8: 633-642.

Zhang, Z. Q.; Giroud, C. and Baltz, T. (1993): Trypanosomaevansi. In vivo and in vitro determination of trypanocide resistance profile. Experimental Parasitology, 77: 387-394. 


\section{بعض الاراسات على التريبانوسوميازيس فى الابل المستورده}

أحمد محمود عطية زيتون ، صفاء سبي حسن حننين ، خالد أحد سبإ الخباز ، صالحين جاد الرب عبا الحمبا

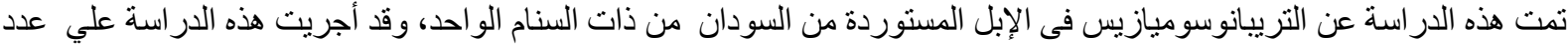

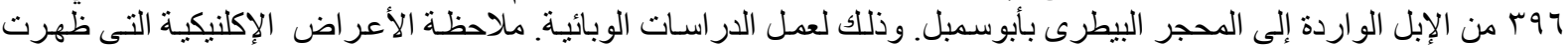

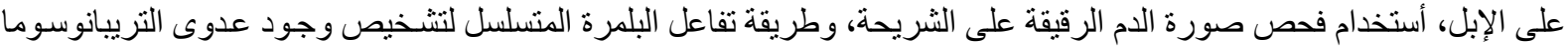

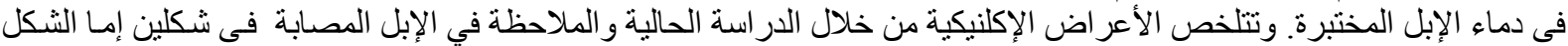

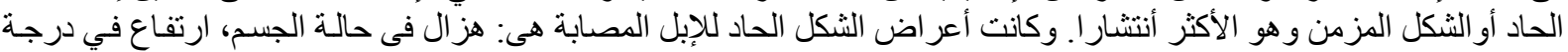

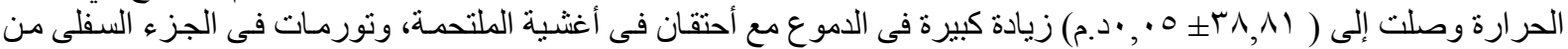

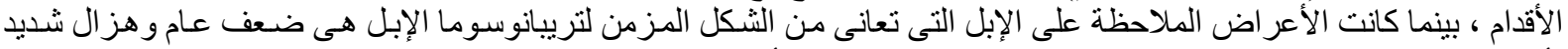

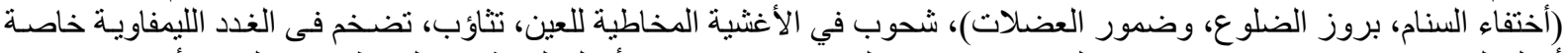

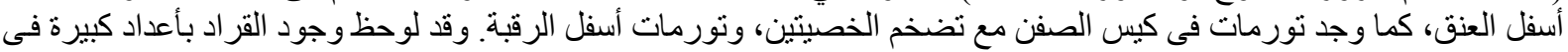

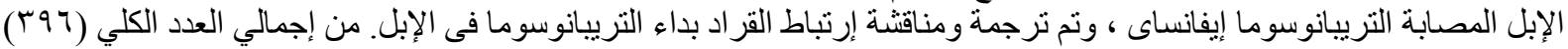

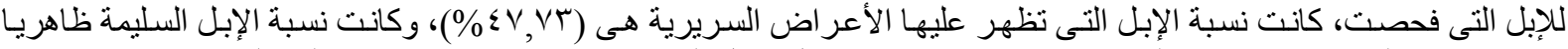

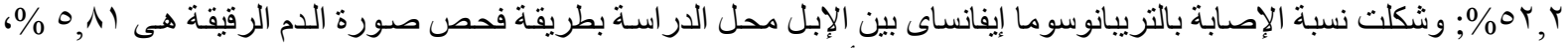

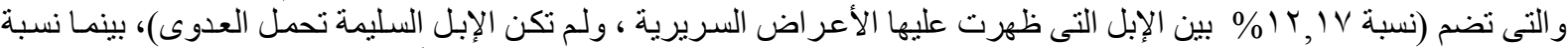

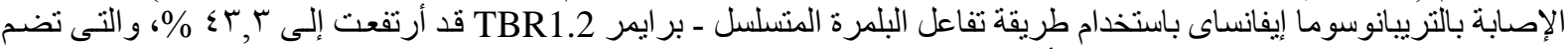

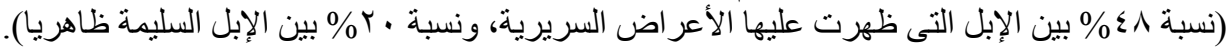

